\title{
Expression of Sry-related genes in the developing genital ridge/mesonephros of the chick embryo
}

\author{
D. McBride, H. Sang and M. Clinton* \\ Division of Development and Reproduction, Roslin Institute (Edinburgh), Roslin, Midlothian \\ EH25 9PS, UK
}

\begin{abstract}
A reverse transcription-polymerase chain reaction approach was used in an attempt to identify a chick homologue to Sry. Gene transcripts from the genital ridge were analysed at the stage of development at which the expression of such a gene might be expected. A number of Sry-related genes expressed in the developing genital ridge of the chick were identified.
\end{abstract}

\section{Introduction}

During embryonic development, the actions of regulatory genes commit the undifferentiated cells of the genital ridge along the testicular or ovarian pathway. The gene responsible for testis determination in mammals has been identified (Gubbay et al., 1990; Sinclair et al., 1990; Koopman et al., 1991). In mice, this gene is designated Sry for Sex determining region, $Y$-chromosome. The Sry protein contains a DNA-binding motif known as the HMG-box, found in a wide variety of proteins that bind to DNA with different degrees of sequence specificity (Nasrin et al., 1991; Harley et al., 1992; Rimini et al., 1995). This region is highly conserved in all mammalian Sry genes sequenced to date, while sequences outside the HMG-box are very poorly conserved between mammalian species (Laudet et al., 1993; Payen and Cotinot, 1993; Tucker and Lundrigan, 1993; Whitfield et al., 1993; Tucker and Lundrigan, 1995). Homologues of the Sry gene are present in all mammalian species so far examined but none have yet been identified in a non-mammalian species.

In birds, the female is heterogametic with regard to sex chromosomes, with one $\mathrm{Z}$ chromosome and one $\mathrm{W}$ chromosome. It would therefore seem unlikely that an identical sex-determining system could operate in birds and mammals. However, it is possibile that an avian homologue to Sry could act as a testis-determining gene if its expression was triggered by a different mechanism from that seen in mammals. The aim of this study was to identify an avian homologue to Sry. Other workers have attempted such studies using approaches based on the polymerase chain reaction (PCR). These studies involve PCR amplification using genomic DNA as template, and, while unsuccessful at identifying an avian homologue of Sry, a number of avian sequences of Sry-related (Sox) genes have been reported (Griffiths, 1991; Coriat et al., 1993). In contrast, a reverse transcription-PCR approach was used to examine gene transcripts in the chick genital ridge at the time of gonadal differentiation, that is, at a time and location that an avian

*Correspondence

Received 7 June 1996. (a)

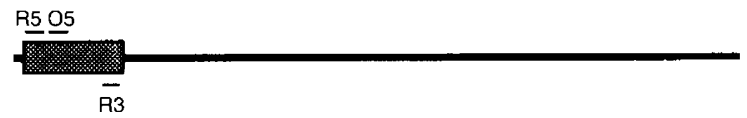

(b)

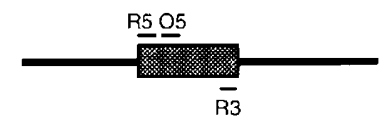

Fig. 1. Schematic representation of mouse Sry (a) and human SRY (b) demonstrating relative positions of PCR primers, R5, O5 and R3 (-). 霜 HMG-box region of protein.

homologue of Sry might be expected to be expressed (Koopman et al., 1990). Combinations of degenerate PCR primers based on the sequences of a number of mammalian $\mathrm{Sry}$ genes were used.

The aim of this study was to identify a number of sequences of Sry-related genes, some of which correspond to avian sequences reported in earlier studies. One of these sequences corresponded to the avian homologue of SOX-9, a gene recently implicated in sex reversal and chondrogenesis in mammals (Foster et al., 1994; Wagner et al., 1994; Wright et al., 1995). This sequence has been used to isolate a genomic clone for chicken SOX-9.

\section{Materials and Methods}

\section{Materials}

Degenerate PCR primers were designed based on the published sequences of mammalian Sry genes. Primers were R5-GTG/CAAGCGACCCATGAATTCA/TTTT/CATC/ GGTG/ATGGT, R3-ATCTTCGAATTCCGAC/TGAGGTT/ CGA/GTAT/CTTG/ATA and O5-AGA/GTGGCT/CCT/AA/ GG/CAGAATTCCAG/AA/CATG. Primers correspond to nucleotides at positions 7-40(R5), 208-239(R3) and 59-84(O5) of the HMG Box of the mouse Sry gene (Fig. 1). For ease of subcloning, primers were designed to include an EcoRI restriction enzyme site. 
1. CCCAGGCGGC TCGAAGGAAG CTGGCTGACC AGTACCCGCA TCTGCACAAC GCCGAGCTCA GCAAGACGCT GGGCAAGCTG TGGAGGCTGC TGAATGAGAG CGAGAAGCGT CCCTTCGTGG AGGAGGCCGA GCGGCTGCGG GTGCAGCACA AGAAGGACCA CCCCGAC

2. TCTAAGATCG AGAGGAGAAA AATCATGGAG CAGTCGCCGG ACATGCACAA CGCGGAGATC TCCAAGCGCC TGGGCAAGCG GTGGAAAATG CTGAAGGACA GCGAGAAGAT CCCCTCCATC CGGGAGGCGG AGAGGCTGCG GCTCAAGCAC ATGGCCGATT ACCCCGAC

3. TCCCGGGGCC AGCGCGGCAA GATGGCACAG GAGAACCCCA AAATGCACAA CTCGGAAATC AGCAAGCGGC TGGGCGCGGA GTGGAAGCTG CTCTCCGAGG CGGAGAAGCG GCCCTACATC GACGAGGCCA AGCGGCTGCG GGCGCAACAC ATGAAGGAAC ACCCCGAC

4. TCCCGGGGCC AGCGGCGGAA GATGGCCCAG GAGAATCCCA AGATGCACAA CTCGGAGATC AGCAAGCGCC TCGGGGCCGA TTGGAAGCTG CTGAGCGATG CCGAGAAGCG GCCCTTCATC GACGAGGCCA AGAGGCTGCG GGCCGTGCAC ATGAAGGAGT ACCCGGAT

5. TCGCAGCACG AGCGCCGCAA GATCATGGAC CAGTGGCCCG ACATGCACAA CGCCGAGATC TCCAAGCGCC TGGGTCGGCG CTGGCAGCTC CTGCACGACT CCGAGAAGAT CCCCTTTGTG AAGGAGGCCG AGCGCCTGCG CGTCAAGCAC ATGGCCGACT ACCCCGAC

6. TCGCAGATCG AACGGCGGAG GATCATGGAG CAGTCGCCCG ACATGCACAA CGCCGAGATC TCCAAGCGGC TGGGCAAGCG CTGGAAGCTG CTCAAGGACA GCGACAAGAT CCCCTTCATC CGGGAGGCGG AGCGGCTGCG CCCTCAAGCA CATGGCGGAC TACCCCGAC

Fig. 2. Nucleotide sequences of representative clones from the six groups of PCR-derived clones (PCR-primer sequences are not shown).

\section{cDNA synthesis}

ISA-Brown eggs from commercial hens were incubated, on the day of lay at $38^{\circ} \mathrm{C} \pm 0.5^{\circ} \mathrm{C}$. After 5,6 and 7 days of incubation embryos (50 per day) were isolated and placed in sterile Petri dishes for dissection of genital ridges/mesonephros. RNA extracted from dissected tissues, from both male and female embryos, was combined and cDNA was synthesized using a commercially available first strand $\mathrm{CDNA}$ synthesis kit (Pharmacia Biotech, St Albans).

\section{$P C R$}

PCR reactions were performed on CDNA templates using primer combinations R5 with R3, and O5 with R3.

PCR reactions were performed in $50 \mu \mathrm{l}$ of $10 \mathrm{mmol}$ Tris$\mathrm{HCl} \mathrm{l}^{-1}, 1.5 \mathrm{mmol} \mathrm{MgCl}_{2} \mathrm{l}^{-1}, 50 \mathrm{mmol} \mathrm{KCl} \mathrm{I}^{-1}, 0.1 \mathrm{mg}$ $\mathrm{ml}^{-1}$ gelatine, $\mathrm{pH} 8.3$, containing $200 \mu \mathrm{mol}$ dNTPs $\mathrm{l}^{-1}$, $1 \mu \mathrm{mol}$ primers $\mathrm{I}^{-\mathrm{I}}$ and 1 unit of Taq polymerase (Boehringer
Table 1. Number of individual clones in each group of Sry-related sequences

\begin{tabular}{lc}
\hline $\begin{array}{l}\text { Sequence } \\
\text { group }\end{array}$ & $\begin{array}{c}\text { Number of } \\
\text { individual clones }\end{array}$ \\
\hline 1 & 21 \\
2 & 19 \\
3 & 11 \\
4 & 1 \\
5 & 3 \\
6 & 4 \\
\hline
\end{tabular}

Mannheim UK, Lewes). After an initial denaturation step of $94^{\circ} \mathrm{C}$ for $2 \mathrm{~min}, \mathrm{DNA}$ was denatured at $94^{\circ} \mathrm{C}$ for $1 \mathrm{~min}$, annealed at $60^{\circ} \mathrm{C}$ for $2 \mathrm{~min}$ and extended at $72^{\circ} \mathrm{C}$ for $2 \mathrm{~min}$. Reactions were subjected to 30 cycles of amplification and 
SQAARRKLAD QYPHLLNAEL SKTLGKLWRL INESEKRPFV EEAERLRVQH KKDHPDYK

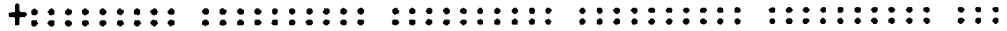

AQAARRKLAD QYPHLHNAEL SKTLGKLWRL INESEKRPFV EEAERLRVQH KKD

SKIERRKIME QSPDMHNAEI SKRLGKRWKM IKDSEKIPFI REAERLRLQH MADYPDYK

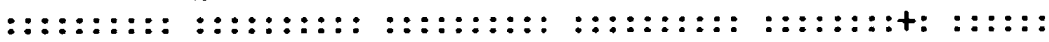

SKIERRKIME QSPDMHNAEI SKRLGKRWKM LKDSEKIPFI REAERLRLKH MADYPD

SRGQRGKMAQ ENPKMHNSEI SKRLGAEWKL LSFAEKRPYI DEAKRLRAQH MKEHPDYK

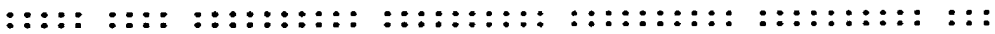

SRGQRRKMAQ ENPKMHNSEI SKRLGAEWKL LSEAEKRPYI DEAKRLRAQH MKE

SRGQRRKMAQ ENPKMHNSEI SKRLGADWKL LSDAEKRPEI DEAKRLRAVH MKEYPDYK

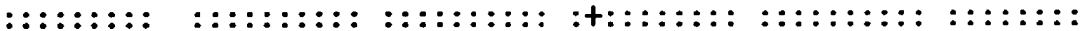

SRGQRRKMAL ENPKMHNSEI SKRLGADWKL LTDAEKRPEI DEAKRLRAVH MKEYPDYK

SQHERRKIMD QWPDMFNAEI SKRLGRRWQL IHDSEKIPFV KEAERLRVKH MADYPDYK

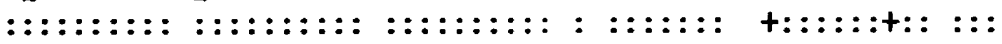

SQHERRKIMD OWPDMHNAEI SKRLGRPWQL LODSEKIPFE REAERLRLKH MAD

SQIERRKTME OSPDMHNAEI SKRLGKRWKL LKDSDKIPFI REAERLRLKH MADYPDYK

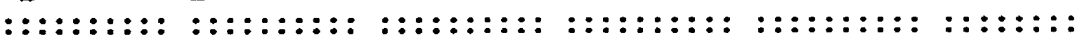
SQIERRKTME QSPDMHNAEI SKRLGKRWKL IJWSDKIPFI REAERLRLKH MADYPDYK
Group 1

Mouse Sox-9

Group 2

Human SOX-11

Group 3

Mouse Sox-14

Group 4

Human SOX-3

Group 5

Mouse Sox-12

Group 6

Human SOX-4

Fig. 3. Predicted amino acid sequences of chicken Sox transcripts compared with protein sequences of mammalian homologues. Blanks indicate non-conservative substitutions; +, conservative substitutions; and :, identical amino acids.

then a final extension step at $72^{\circ} \mathrm{C}$ for $5 \mathrm{~min}$. PCR products were separated on a $1.0 \%$ agarose gel and bands visualized under UV light after ethidium bromide staining (Maniatis et al., 1982).

PCR products were gel purified, digested with EcoRI and subcloned into Bluescript KS M13 (Stratagene Ltd, Cambridge). Competent Escherichia coli JMI09 cells were transformed and plated on Luria-Bertani (LB)-ampicillin plates.

Transformant clones were picked and cultured overnight in LB medium containing ampicillin.

\section{Sequencing}

Plasmid DNA was prepared using commercially available reagents (Qiagen Ltd, Dorking) and sequenced by the dideoxy chain termination method using a Sequenase kit (Amersham International plc, Slough). Sequences were compared against international nucleotide and protein databases using the Blast package of analysis programmes (Altschul et al., 1990).

\section{Genomic clones}

A chick genomic library in lambda EMBL-3 was plated on $E$. coli strain NM621 and screened using the protocol of Maniatis et al. (1982). Purified insert from PCR clone pBS-cSOX9 was labelled using the Ready-To-Go kit (Pharmacia Biotech) for use as probe. DNA from positive EMBL-3 clones was used as template in PCR reactions using primers R5 and R3. The resulting $\mathrm{PCR}$ product was purified on a gel, subcloned into Bluescript KS M13 and sequenced.
Table 2. Degree of identity of chick sequences with most closely related mammalian sequence

\begin{tabular}{lcc}
\hline Chick sequence & $\begin{array}{c}\text { Nucleotide } \\
(\%)\end{array}$ & $\begin{array}{c}\text { Amino acid } \\
(\%)\end{array}$ \\
\hline CSox-9 & 90 & 98 \\
CSox-11 & 90 & 98 \\
CSox-14 & 86 & 98 \\
CSox-3 & 86 & 96 \\
CSox-12 & 88 & 92 \\
CSox-4 & 93 & 100 \\
\hline
\end{tabular}

\section{Results}

Reverse transcription-PCR was used to examine Sry-related transcripts in the genital ridge/mesonephros of developing chick embryos. The two primer combinations were used and PCR products of the expected sizes, $233 \mathrm{bp}$ and $181 \mathrm{bp}$, were obtained. PCR products were digested with EcoRI, get purified and subcloned into Bluescript KS M13. A total of 60 clones was analysed and the sequences fell into six groups of identical clones (Table 1). Nucleotide sequences of representative clones from each group are shown (Fig. 2). The sequence of each group of clones was compared with that of mammalian Sry and Sox genes. Although overall, Sry genes are poorly conserved between species, the HMG-box regions of individual Sox genes, including Sry, show a high degree of conservation (Griffiths, 1991; Coriat et al., 1993; Laudet et al., 1993; Payen and Cotinot, 1993; Tucker and Lundrigan, 1993; Whitfield et al., 1993). On this basis, the sequences obtained in 
1 CCCAGGCGGC TCGAAGGAAG CTGGCTGACC AGTACCCGCA TCTGCACAAC

51 GCCGAGCTCA GCAAGACGCT GGGCAAGCTG TGGAGGTGAG CGGGAGGTGG

101 GAGCGATGCC TGGGGTGGGC GGGGGGACGC AGCCTGCAGA GTTTGCTCCG

151 GCTGTGACGC GCGAGGAGGA GAGAGGAAAG GGAGGGAGAG GATGGTTGGA

201 AGCCTGGAAA AGTTGCCGCA AAGTTTTGCA TGCGCTGGCA AAGTTGTTCG

251 GCGGAATAGG AGGGGGAGAG CAGGGCAAGG AGAGCCTGGG CTGCCCTCTG

301 CTCCTGCAAA AGGTTTTATG CTGCTTGAGC CGTGCCCTGT GTGTGCTGCA

351 GCCGGGGGAG CGCTTGGTGA TTGTGCAGGG GAAGCGATGG GCCTAGATTG

401 CATCAGCTCT GTGCAGAGCG AGGGGAGGGG GCAAAAGCTG CCAACCCCCG

451 GGTGGGTGCC CAGGGGCGGC TGGGTGCCCT CCGCCTTCCA AAATAAGGCA

501 GGGAGGGGTG AAAATCAGGA GGCAAGTGAG TCACCTGGCT GCCAATGAGT

551 GTGACTGCAG AAAGGAGGGG CGGAGGGGAA TCCTAAATCC ACAGCGGGAG

601 GAGAAAGTGG TGAGCAACTC TGGTCCTGGC AGCCGGCGCG AGAGCCGTCA

651 CCCACAGTGC CCGGGGATGG GGGAGCTGAG GAGCACTGTG CTCTCACACC

701 TCTCGTTTGG TCATTGAAAC GCGGGGTGTC AACCAGCATG TGCCCCAAAG

751 TGAGGGTTCA GTGCTGGAAG GGGGGAGGTC GCATCCCTGT TTGTGGGGAC

801 TGGGAGAGGT TTGGGGCTGA TGTCAATGGC AGAGCGGAGG GAAACACTTG

851 CGCCTCTCCC CCGTGAGCTG CAGCTGACCC CTCACCGTGT TTTCCCCCCC

901 CTTCCCCATC CTCCTCAGGC TGCTGAATGA GAGCGAGAAG CGTCCCTTCG

951 TGGAGGAGGC CGAGCGGCTG CGGGTGCAGC ACAAGAAGGA CCACCCCGAC 1001 TACAA

Fig. 4. Sequence of genomic cSoxg clone, pBS 71101. Splice donor and acceptor sequences are underlined (PCR-primer sequences are not shown).

this study were compared with nucleotide databases and assigned as homologues of the most closely matching mammalian sequences. None of the amplified sequences corresponded to a chick homologue of Sry, but all sequences represented members of the Sox gene family (Fig. 3).

The predicted amino acid sequences of the six groups of clones were compared with the amino acid sequences of mammalian Sox genes. This enabled identification of the probable mammalian homologues: Group I sequences differ by one amino acid from mouse Sox 9; Group 2 sequences differ by one amino acid from human SOX11; Group 3 sequences differ by one amino acid from mouse Sox 14; Group 4 sequences differ by two amino acids from human $\mathrm{SOX} 3$; Group 5 sequences show four amino acid differences from mouse Sox12; and Group 6 sequences are identical to human SOX4.

To avoid confusion, the nomenclature of Wright et al. (1995) was adopted and these clones were designated cSox9, cSoxI1, cSox14, cSox3, cSox12 and cSox4. A summary of comparisons of chick sequences with mammalian homologues is shown (Table 2).

One of these sequences (Group 1) represents the chick homologue of Sox-9, a gene recently implicated in sex reversal in mammals. This clone was used to screen a chick genomic library. Positive clones were used as a template in PCR reactions with the primers $R 5$ and $R 3$. The resulting PCR product, designated pBS 71101, contained 1066 bp rather than 
the expected $233 \mathrm{bp}$. The $1066 \mathrm{bp}$ fragment was subcloned and sequenced. Analysis of this sequence was found to comprise the HMG box of $\operatorname{cSox} 9$ with 833 of intronic sequence flanked by consensus splice sites. The nucleotide sequence of this genomic clone is shown (Fig. 4).

\section{Discussion}

Reverse transcription-PCR was used to examine the Sry-related transcripts present in the genital ridge/mesonephros of chick embryos between day 5 and day 7 of development. In terms of gonadal development, days 5-7 of embryogenesis in chicks correspond to days 10-12 in mice, and represent the period during which Sry is expressed. It could reasonably be assumed that should a Sry homologue function in the same manner in the chick, the gene would be expressed at this time in the developing gonad. The failure to detect expression of an Sry homologue in the differentiating genital ridge coupled with previous unsuccessful attempts to identify chick Sry suggest that the mechanism of sex determination in chicks does not depend on this developmental switch.

Expression of a number of Sry-related Sox genes was detected, although practical difficulties in isolating genital ridge tissues free from contaminating mesonephric tissue made it impossible to be certain that this expression occurred in the genital ridge. A mutation in one of these Sox genes has been implicated in sex-reversal in mammals (Foster et al., 1994; Wagner et al., 1994). A chick genomic library was screened using the PCR clone cSox9 as a probe to study this gene in chickens. DNA extracted from positive clones was used as a template in PCR reactions containing the HMG box primers. The PCR product was larger than predicted, suggesting the presence of intronic sequences, which was subsequently confirmed by DNA sequence analysis. The position of the intron within the DNA binding motif of c Sox 9 corresponds exactly to that recently published for mouse Sox 9 (Wright et al., 1995).

In conclusion, these results suggest that the sexdetermination mechanism in chicks is not dependent on a homologue of the mammalian testis determining gene. However, expression of a Sry-related gene also thought to be involved in mammalian gonadal development was demonstrated in the genital ridge/mesonephros at a time co-incident with chick gonadal differentiation.

The authors thank P. Koopman for assistance in assigning clones as homologues to mammalian sequences. This work was supported by a commission from the Ministry of Agriculture, Fisheries and Foods.

\section{References}

Altschul SF, Gish W, Miller W, Meyers EW and Lipman DJ (1990) Basic local alignment search tool Journal of Molecular Biolog:/ 215 403-410

Coriat A-M, Muller U, Harry JL, Uwanogho D and Sharpe PT (1993) PCR amplification of SRY-related gene sequences reveals evolutionary conservation of the SRY-box motif PCR Methods and Applications 2 218-222

Foster JW, Dominguez-Steglich MA, Guioli S, Kwok C, Weller PA, Stevanovic M, Weissenbach J, Mansour S, Young ID, Goodfellow PN, Brook JD and Schafer AJ (1994) Campomelic dysplasia and autosomal sex reversal caused by mutations in an SRY-related gene Nature 372 525-530

Griffiths R (1991) The isolation of conserved DNA sequences related to the human sex-determining region $Y$ gene from the lesser black-backed gull (Larus fuscus) Proceedings of the Royal Society of London 224 123-128

Gubbay J, Collignon J, Koopman P, Capel B, Economou A, Munsterberg A, Vivian N, Goodfellow P and Lovell-Badge R (1990) A gene mapping to the sex determining region of the mouse $Y$ chromosome is a member of a novel family of embryonically expressed genes Nature 346 245-250

Harley VR, Jackson DI, Hextall PJ, Hawkins JR, Berkovitz GD, Sockanathan S, Lovell-Badge $R$ and Goodfellow PN (1992) DNA binding activity of recombinant SRY from normal males and XY females Science 255 453-456

Koopman P, Munsterberg A, Capel B, Vivian N and Lovell-Badge R (1990) Expression of a candidate sex-determining gene during mouse testis differentiation Nature $\mathbf{3 4 8} \quad 450-452$

Koopman P, Gubbay J, Vivian N, Goodfellow PN and Lovell-Badge R (1991) Male development of chromosomally female mice transgenic for Sry. Nature $\mathbf{3 5 1}$ $117-12$ I

Laudet V, Stehelin D and Clevers H (1993) Ancestry and diversity of the HMG box superfamily Nucleic Acids Research 21 2493-2501

Maniatis T, Fritsch EF and Sambrook J (eds) (1982) Molecular Cloning: a Laboratory Manual Cold Spring Harbour Laboratory, New York

Nasrin N, Buggs C, Kong XF, Carnazza J, Goebl M and Alexander-Bridges M (1991) DNA-binding properties of the product of the testis-determining gene and a related protein Nature 354 317-320

Payen EJ and Cotinot CY (1993) Comparative HMG-box sequences of the Sry gene between sheep, cattle and goats Nucleic Acids Research 212772

Rimini R, Pontiggia A, Spada F, Ferrari S, Harley VR, Goodfellow PN and Bianchi ME (1995) Interaction of normal and mutant SRY proteins with DNA Philosophical Transactions of the Royal Society of London 350 215-220

Sinclair AH, Berta P, Palmer MS, Hawkins JR, Griffiths BL, Smith MJ, Foster JW, Frischauf AM, Lovell-Badge R and Goodfellow PN (1990) A gene from the human sex-determining region encodes a protein with homology to a conserved DNA-binding motif Nature 346 240-244

Tucker PK and Lundrigan BL (1993) Rapid evolution of the sex determining locus in Old World mice and rats Nature 364 715-717

Tucker PK and Lundrigan BL (1995) The nature of gene evolution on the mammalian $Y$ chromosome: lessons from Sry. Philosophical Transactions of the Royal Society of London $35022 \mathrm{I}-227$

Wagner T, Wirth J, Meyer J, Zabel B, Held M, Zimmer J, Pasantes J, Bricarelli FD, Keutel J, Hustert E, Wolf U, Tommerup M, Scempp W and Scherer G (1994) Autosomal sex reversal and campomelic dysplasia are caused by mutations in and around the SRY-related gene SOX9 Cell 79 1111-II20

Whitfield LS, Lovell-Badge R and Goodfellow PN (1993) Rapid sequence evolution of the mammalian sex-determining gene SRY Nature 364 713-715

Wright E, Hargrave MR, Christiansen J, Cooper L, Kun J, Evans T, Gangadharan U, Greenfield A and Koopman P (1995) The Sry-related gene Sox 9 is expressed during chondrogenesis in mouse embryos Nature Genetics 9 15-20 